\title{
Dear Readers
}

\section{Bob Kleinmann}

Published online: 3 August 2013

(c) Springer-Verlag Berlin Heidelberg 2013

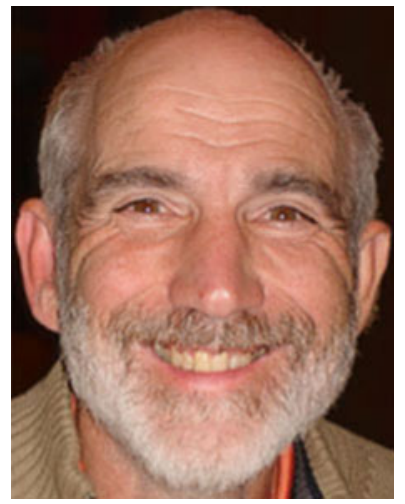

Dear Readers,

This issue was supposed to be composed of expanded, updated versions of the best papers from last year's conference in Western Australia, but some of the authors took a while to get their papers submitted, reviewed, and revised and I just finalized the editing of the last of those, which meant that it was not possible to get it through the rest of the publication process, given that the issue you are holding in your hands had to be finalized by late July. So, we will try to get that issue in print for December; if you see the next issue starting off with another paragraph like this, you will know that we didn't quite make it. But the failure of some of those authors to get everything together in time created an opportunity for other papers to move ahead of them in the queue. And I do not believe that any of you will be disappointed with this issue. Once again, the papers published here represent a wide range of topics (everything from lab studies to field studies to modeling) and, equally satisfying to me, a very full international profile, with only one country (China) with two (more about China, later). The other countries represented include Australia, Ireland, the Slovak Republic, Great Britain, Turkey, and the USA.

B. Kleinmann $(\square)$

Pittsburgh, PA, USA

e-mail: editor@MWEN.info
As mentioned above, I am writing this in July, which means that I have not yet attended the 2013 IMWA conference in Golden. I am certain that it will be a great meeting, as the organizers have been working very hard on it. However, since this issue won't be published until after the conference, I can announce here that this journal's International Editorial Board has once again decided on which of the great papers published in 2012 was the best. Please pause here for an imaginary drum roll... The paper selected as Mine Water and the Environment's best paper of 2012 is: Characterisation Leaching Tests and Associated Geochemical Speciation Modelling to Assess Long Term Release Behaviour from Extractive Wastes (issue 2, pages 92-103, DOI 10.1007/s10230-012-0182-8), by Hans Albert van der Sloot and Andre van Zomeren, who are both with the Hans van der Sloot Consultancy, which is based in Dorpsstraat, the Netherlands. If you, by chance, do not remember that paper, please take the time to go back and re-read it; you will definitely find it worthwhile. I hope to have a picture of the winners holding their award here in this spot next issue.

Meanwhile, it is not too early to start thinking about attending the 2014 IMWA conference, which is going to be held in Xuzhou, China, from August 18-22, 2014 (http://www.IMWA2014.info). The theme of the 2014 China meeting will be: An Interdisciplinary Response to Mine Water Challenges. This will be the first time IMWA has scheduled a meeting anywhere in Asia and I truly hope that it will allow some IMWA members who have never made it to one of our conferences an opportunity to do so, and, at the same time, that this location will provides some of us who have always wished to visit China an opportunity and a reason to do so. Alright, perhaps an IMWA conference in Tahiti would be even nicer, but I wouldn't recommend saving your travel funds until that comes about. 